\title{
International Roaming of Mobile Services: The Need for Regulation
}

\author{
Morten Falch \\ CMI, Aalborg University Copenhagen, Denmark \\ falch@cmi.aau.dk
}

\begin{abstract}
This section discusses the need for regulation of international roaming charges. This is done through analysis of the EU experiences by a heavy handed price regulation of roaming services.
\end{abstract}

Keywords: International roaming, EU regulation, regulation of mobile services.

\section{Introduction}

High international roaming charges have been a matter of concern in several countries. The Australian Competition and Consumer Commission concluded in 2005 that both wholesale and retail roaming charges are too high, but have not turned into direct price regulation. The Arab Regulators' Network is working on different models for introducing price regulation in the Arab region.

Regulation of international roaming is more complicated than regulation of other telecom services for two reasons. First, the market structures on mobile markets are different than on markets for fixed services. Second, regulation of international roaming is difficult to implement at the national level as operators from more than one country are involved.

Markets for fixed services are dominated by incumbent operators having their own fixed infrastructures. Regulatory intervention demanding open access to these networks will benefit new entrants and promote competition at least in the short term. In mobile markets the situation is a bit different as there are more mobile infrastructures on each market. It is therefore less obvious what market implications will be, if a similar kind of obligation is posed on mobile networks.

Partly for these reasons, no regulatory intervention in international roaming charges within the EU area was made before a legislation addressing this specific issue was adopted in June 2007. Although it was recognized that the roaming issue included data as well as voice services, only voice was addressed in the first legislation. Roaming regulation of data was seen to be an even more complicated issue, which needed more analysis before action could be taken.

According to the New Regulatory Framework (NRF), international roaming is defined as a separate market, but the national market studies prepared according the guidelines of NRF did not lead to price regulation in the EU member states. Regulation of this market seems to be more difficult to handle by national regulators than regulation of markets for other telecom services. 
The legislation on regulation of international roaming made by the EU introduces price caps in both retail and wholesale markets for international roaming of voice services [10]. The major argument for such a heavy handed regulation is that international roaming prices hitherto have been way above cost based prices, and that roaming charges represent a major barrier towards growth in international mobile communication within the EU. The proposal resulted in a reduction in international roaming prices with more than $50 \%$. The question is how this intervention will affect the market in the long term. Will a temporary price cap be enough to keep prices down or will it be necessary to introduce a more permanent type of regulation? Another question is if such regulation can be made without having a negative impact on competition and innovation.

\section{Techno-Economic Analysis of Roaming Costs}

This section will look at the demand and supply conditions on the roaming market from a techno-economic point of view, and discuss the how the current experiences on regulation of international roaming of voice services can be applied in the design of regulation of data roaming:

- Mobile origination (MO)

- Mobile/Fixed termination (MT/FT)

- International Transit (IT)

- Roaming specific costs (RSC)

Mobile origination includes the cost of initiating the call and for connecting the caller's mobile terminal with the core network. Mobile termination includes the cost related to bring the call from the receiver's core network to his/hers mobile terminal. The international transit costs include the costs related to connect the callers and the receiver's core networks. Roaming specific costs include costs directly related to the roaming transaction. This is the kind of costs, which are not included in a normal international call.

The costs of mobile origination are comparable to those of mobile termination. For data services it may even be difficult to distinguish between origination and termination. For voice mobile termination rates are subject to regulation within the $\mathrm{EU}$ and are in principle cost-based. Mobile termination rates per minute varied in October 2007 before regulation was implemented between $€ 0.0206$ in Cyprus and $€$ 0.1882 in Bulgaria. However in most countries the rates were close to the EU average of $€ 0.0967$. The European average for local fixed termination is $€ 0.0083$.

International transit costs depend on the inter-operator tariffs agreed between operators. These tariffs are confidential, but the costs are far below the cost of origination and termination.

\section{Structure of the Market for Roaming Services}

The market for international for international roaming services differs in many ways from the markets for other mobile services. The special characteristics of this market 
have been studied in a number of reports and research papers, e.g., [9]. A formal mathematical model of the market is presented in [8] and further extended [7]. The Commission has also created a model in their impact assessment report [1].

\subsection{Demand Conditions - Retail}

According to the impact assessment report international roaming is used by at least 147 million EU citizens, of whom 110 million are business customers, while 37 million are travelling for leisure purposes [1].

Although international roaming is an important service used by a large group of customers, most subscribers use this service only occasionally, and the level of roaming charges are relatively unimportant for the total cost paid by a mobile subscriber. Therefore only few subscribers will let their choice of operator depend on the roaming charges offered.

Another characteristic of roaming services is that it involves use of many different visiting networks, so even high volume users may only gain a minor benefit by reductions in wholesale roaming charges by a particular operator.

An alternative to international roaming is to acquire a local SIM-card and in this way to avoid paying roaming charges. This solution is in particular attractive for placing local calls abroad, and is used by many potential high volume users of international roaming.

Even though the level of roaming charges is not used as a parameter in competition, it might still be a price elastic service. According to a European fieldwork on roaming prepared in 2006, the main reason for using the mobile phone less while travelling abroad is excessive costs, and six out of ten Europeans would use their phone abroad if prices were more attractive [3].

The impact assessment report assumes in its analysis price elasticity between -0.55 and -1.20 [1]. If this is correct, there will be substantial welfare gains associated with price reductions towards costs based prices (If elasticity are -1.20 , even operators revenue will increase).

It should however be noted that the majority of the subscribers using international roaming are business customers, which are likely to be less price sensitive than private customers. Another factor, which may lead to low price sensitivity is lack of transparency. If users are unaware of the actual prices, price reductions will not lead to a higher demand. Use of SMS informing about roaming charges sent to subscriber arriving in country makes the prices more transparent and may therefore increase price elasticity.

International roaming is an international service. International roaming is demanded by customers, when they are abroad. The demand for roaming in a certain area depends therefore not on the number of local customers, but on the number of visitors. Roaming may therefore constitute a major share of the traffic and revenue in tourist areas.

\subsection{Supply Conditions - Retail}

Suppliers at the retail market include all mobile operators at the national market. As with most other telecom services, the retail market is more competitive than the wholesale market as it includes network operators as well as virtual operators and service providers. Although the suppliers are identical to those offering other mobile services, the market seems to be less competitive. At least the mark-ups demanded by the operators are much 
higher than mark-ups on other mobile services. The reasons for this is that international roaming is bundled with the subscription for domestic mobile services (unless the customer buys a new SIM-card), are that customers consider roaming rates to be of minor importance compared to rates for other services.

\subsection{Demand Conditions - Wholesale}

International roaming services are demanded by most mobile operators from their retail customers. Only few operators with an international footprint are able to handle part of their roaming within their own network, while others other - including virtual network operators - will need to buy roaming services from local mobile operators.

Operators will charge their retail customers a price covering the wholesale roaming costs plus a mark-up covering various retail costs such as billing and customer handling. The incentive to reduce wholesale costs depends on how price sensitive the retail customers are. In addition, for technical reasons, it is not always possible for the home mobile network operator (HMNO) to choose the visiting mobile network operator (VMNO) offering the lowest price.

\subsection{Supply Conditions - Wholesale}

Non-roaming international mobile calls can be handled within the same framework as fixed international calls. Before the liberalization, international fixed calls were priced according to the international accounting rates. The system with international accounting rates dates back to 1865 , when the predecessor of the International Telecom Union (ITU) was created. The rate determines how much an operator in one country needs to pay for termination of a call in another country. These rates are negotiated on a bilateral basis and are loosely connected to the costs of maintaining end-to end facilities between the two countries [6].

Payments of international roaming calls are organized in a similar way as other international calls: The call is handled by the operator, where the call is originated. If this involves use of services from other operators, these operators are paid wholesale charges by the originating operator.

In international roaming the call is originated in a visited network and the visited network operator (VMNO) will therefore charge the home network operator (HMNO), holding the subscription of the caller, in order to cover its costs. This payment is settled through the Transferred Accounting Procedure (TAP) by use of Inter Operator Tariffs (IOT) [5].

For receiving international roaming call, the situation is slightly different. Here, the caller will pay for the price for termination of the call in the home network of the roaming subscriber. The HMNO will then transfer the call to the VMNO, who will receive the usual mobile termination rate for terminating the call. In addition to this, the HMNO must pay the international transit charge for a call. Thus the IOTs used for originating roaming calls are not used in this case.

The number of suppliers of roaming services is the same as the suppliers of wholesale mobile services in the respective countries. In most countries all mobile network operators are required to provide roaming services to foreign operators. Thus the number suppliers is 3-4 in most of the EU countries, and it could be expected that 
the level of competition on roaming services should be at a level similar to that for wholesale provision of other mobile services.

However, IOT have not followed the same decreasing price trends as wholesale charges for other mobile services. Up to 1998 IOTs were based on normal network tariffs for local call with a mark-up at $15 \%$ [8]. But since then local tariffs have declined due to price competition. IOTs have not been subject to the same kind of competition, operators within the same country use similar IOTs, and if they relate to normal network tariffs they are set according to the highest rates offered.

There are a number of reasons for this:

- Technical: Limitations in the choice of VMNO;

- Tariffs are agreed on reciprocal basis; and

- Demand conditions and lack of transparency.

As noted above, it is not always possible for the HMNO to choose the VMNO with lowest IOT. This implies that suppliers of roaming services cannot gain market shares by reducing their roaming charges. Market shares of VMNOs are independent of their charges, and therefore, there is no incentive to lower charges as it just will decrease revenues.

IOTs remind in many ways international accounting rates. Usually agreements are reciprocal in the sense that IOTs are independent on the direction of the call. In a market where competition is limited, the HMNO and the VMNO have a common interest in keeping IOT at a high level. The VMNO will get higher revenue for providing the roaming, the HMNO will able to transfer the roaming costs to its retail customers, and will therefore not suffer from this. When a roaming call is made in the opposite direction it is the other operator who benefits.

The international accounting rates contributed to keep international telephone charges at an artificial high level for many years, and prices came down only when it became possible for retail customers to choose an alternative international operator offering lower charges.

The final point to mention is the impact demand conditions and lack of transparency. In elastic demand caused by lack of market transparency as well as other factors implies that suppliers are less eager to reduce costs. For instance there is no incentive to solve the technical complications related to choosing the cheapest VMNO, if cost reductions don't lead to increased traffic demand.

\section{EU Regulation of International Roaming Charges}

The EU regulation includes regulation of wholesale as well as retail charges. The first proposal from the Commission linked the prices paid for international roaming to prices paid by customers for ordinary mobile calls in their home country [2]. This home pricing principle was replaced by a "European Home Market Approach" in the revised proposal, in which the same maximum price limits are applied in all the EU member states. In the final proposal adopted by the Parliament, the concept of a Eurotariff is used for the maximum price that operators are allowed to charges their customers for international roaming calls within the EU area. The Europe-wide maximum tariffs are defined both for wholesale and retail charges. 
Table 1. Eurotariff maximum price while abroad (€-cents per minute) [4]

\begin{tabular}{|l|l|l|l|l|}
\hline & Making a call & $\begin{array}{l}\text { Receiving a } \\
\text { call }\end{array}$ & $\begin{array}{l}\text { Sending an } \\
\text { SMS }\end{array}$ & $\begin{array}{l}\text { Receiving an } \\
\text { SMS }\end{array}$ \\
\hline Summer 2009 & 43 & 19 & 11 & Free \\
\hline Summer 2010 & 39 & 15 & 11 & Free \\
\hline Summer 2011 & 35 & 11 & 11 & Free \\
\hline
\end{tabular}

For data services regulation was introduced 1 July 2009. This regulation limits the price for sending a text message while abroad at $€ 0.11$. Receiving an SMS in another EU country will remain free of charge. The cost of surfing the web and downloading movies or video programs with a mobile phone while abroad by introducing a maximum wholesale cap of $€ 1$ per megabyte downloaded. This limit will be decreased each year. In addition consumers are protected from "bill shocks" by introduction of a cut-off mechanism once the bill reaches $€ 50$, unless they choose another cut-off limit.

\section{Discussion}

Regulation of international roaming is more complicated than regulation of other telecom services for two reasons. First the market structures on mobile markets are different than on markets for fixed services. Markets for fixed services are dominated by one incumbent operator on each market who has its own fixed infrastructure. Regulatory intervention demanding open access to this network will benefit new entrants and promote competition at least in the short term. In mobile markets, the situation is slightly different as more competing mobile infrastructures are available. It is therefore less obvious what the market implications will be, if a similar kind of obligation is imposed on mobile networks. Second, regulation of international roaming is difficult to implement at national level as operators from more than one country are involved.

For these reasons, a common framework for regulation was not adopted at EU level before 2007. International roaming was defined as a separate market in the market definitions applied in the EU regulatory framework, but the implementation of the new telecom regulation package has not led to any intervention on this market at national level. Market studies for this particular market were among the last to be implemented. In August 2006 market analyses for other telecom services had more or less been completed in most countries, but only Finland had made a decision on international roaming; here the conclusion was that the market was competitive. Since then, no other member states have decided to intervene at the market for international roaming. Regulation of the market for international roaming seems to be more difficult for national regulators to handle than regulation of markets for other telecom services.

The proposal for regulation of international roaming put forward by the EU Commission suggested the introduction of price caps in both retail and wholesale markets for international roaming. The major argument for such heavy-handed 
regulation was that international roaming prices were much higher than cost-based prices, and that roaming charges represented a major barrier towards growth in international mobile communication within the EU.

An interesting aspect of the proposal from the Commission is the use of a European home-market approach, which implies use of common price caps for all EU member states. This implies that determination of price caps are moved from national to European level. This may therefore be seen as a step towards decreasing the power of national telecom authorities and strengthening regulation at EU level. A common price cap improves transparency for consumers, but it may create a situation where operators in high cost countries may have difficulties in covering their costs in full. It may also create strange pricing schemes, where international roaming becomes cheaper than national roaming.

Both wholesale charges and retail charges have been subject to intensive debate. From the beginning operators were very much against any form of regulation, in particular at the retail level. In spite of amble documentation proving excessive rates without any relationship to costs, it is claimed that there is effective competition on the international roaming market.

Also some Governments have been very reluctant towards regulation. In particular in tourist destinations in Southern Europe, international roaming has proved to be an important source of income.

The EU intervention is a compromise between those asking for cost based roaming charges and the interests of operators - particular those operating in major tourist destinations. Nevertheless seen from the consumers' point of view, it is a considerable improvement compared to the former situation, and it was implemented with an impressive speed (less than one year after the proposal from the Commission was published). It is also a move away from regulation based on more or less objective economic evidence towards regulation based on political negotiations between parties with conflicting interests.

Open Access. This article is distributed under the terms of the Creative Commons Attribution Noncommercial License which permits any noncommercial use, distribution, and reproduction in any medium, provided the original author(s) and source are credited.

\section{References}

1. CEC: Impact Assessment of policy options in relation to a Commission Proposal for a Regulation of the European Parliament and of the Council on Roaming on Public Mobile Networks within the Community, Brussels (2006)

2. CEC: Roaming - Fieldwork September - October 2006, Special Eurobarometer European Commission no. 269, Brussels (2007)

3. CEC: How much do you pay when you use your mobile phone abroad?

4. http://ec.europa.eu/information_society/activities/roaming/ tariffs / (accessed November 20, 2011)

5. Gullstrand, C.: Tapping the Potential of Roaming (2007), http: / / www.gsmworld.com/using/billing/potential.shtml (retrieved January 15,2008 ) 
6. ITU: Direction of Traffic, 1996: Trends in International Ttelephone Tariffs, ITU/Telegeography Inc. (1996)

7. Lupi, P., Manenti, F.: Roaming the woods of regulation: public intervention vs firms cooperation in the wholesale international roaming market, Universita' degli Studidi Padova (2006)

8. Salsas, R., Koboldt, C.: Roaming free? Roaming network selection and inter-operator tariffs. Information Economics and Policy (16), 497-517 (2006)

9. Stumpf, U.: Prospects for improving competition in mobile roaming. In: 29th TPRC, Alexandria, Virginia, U.S.A., October 27-29 (2001)

10. Sutherland, E.: The Regulation of International Mobile Roaming. INFO (10), No. 1, 13-24 (2008) 